\title{
Genetic Divergence Studies in Cultivated Tetraploid Finger Millet [Eleusine coracana (L.) Gaertn] genotypes using $\mathrm{D}^{2}$ analysis
}

\author{
A. E. Sunil Subramanya* and R. L. Ravikumar \\ Department of Plant Biotechnology, University of Agricultural Sciences, \\ GKVK Campus, Bangalore, India \\ *Corresponding author
}

A B S T R A C T

\section{Keywords}

Finger millet, Genetic divergence, D2 analysis, cluster mean

Article Info

Accepted:

15 December 2019

Available Online:

20 January 2020
The analysis of genetic diversity using $\mathrm{D}^{2}$ statistics clustered 33 selected genotypes of cultivated finger millet into ten different clusters. The cluster I had 8 genotypes and cluster II and IV had 9 genotypes each. The remaining clusters had only one genotype each. The inter cluster distance was highest $(\mathrm{D}=46.61)$ between cluster VII (GE4568) and cluster VIII (GE1200) and between cluster VII (GE4568) and cluster II $(\mathrm{D}=42.22)$. The trait days to 50 per cent flowering contributed more towards the genetic divergence of 33 selected finger millet genotypes. The cluster VII having solitary genotype GE4568 had the highest cluster mean value for grain yield per plant, total ear head weight per plant, main ear head weight and shoot dry weight. Similarly, cluster III having solitary genotype GE5118 had the highest cluster mean value for plant height, main ear head length, finger length and finger width. The genotypes GE4568 and GE5118 were emerged as most divergent genotypes with higher mean per se performance for many of the yield and yield related traits, which can be effectively utilized in hybridization programme to generate highly variable segregating population to complement all the seed yield and yield related traits to produce superior cultivar.

\section{Introduction}

Finger millet [Eleusine coracana (L.) Gaertn] is an allotetraploid, self-pollinated annual crop belongs to the genus Eleusine and family Poacaeae. The importance of finger millet as a climate resilience crop mainly derives from its outstanding attributes such as nutritional quality, stress adaptation, health benefits and also as a staple foodwith excellent grain storage quality because of its small size and high polyphenol content substantiating the dietary needs and income of many rural households (Goron and Raizada, 2015; Sood et al., 2019). In India, finger millet is cultivated in an area of 11.94 lakh hectares with 19.85 lakh tons production and 1662 $\mathrm{kg} / \mathrm{ha}$ productivity, predominantly grown in 
the states of Karnataka, Uttarakhand, Maharashtra, Tamil Nadu, Odisha, AndhraPradesh, Jharkhand, Gujarat, West Bengal, Bihar and Chhattisgarh (www.indiaagristat.com, 2019). The nutritional significance of finger millet can be comparable to major cereals and it has highest calcium content $(344 \mathrm{mg} / 100 \mathrm{~g})$ among all the cereals (Chethan and Malleshi, 2007). Although, finger millet has a rich diversity and the vast germplasm pool of finger millet still remains uncharacterised and yet to be broadly investigated for understanding the existing diversity, evolutionary lineage and taxonomic relationship, which renders a major constraint in identification of genetically diverse germplasm with a useful traits for effective utilization in crop improvement programme (Upadhyaya et al., 2006).

Therefore, it is essential to have a reliable knowledge on existence of diversity among the population to select genetically diverse germplasm for hybridization programs for better crop improvement. The $\mathrm{D}^{2}$ statistics, a concept was developed by Mahalanobis(1936) and Rao (1952) suggested the utilization of this techniques as a rational criterion for assessment of genetic diversity for identifying diverse parent of origin. This method as certain the degree of diversification and also the relative portion of each component trait to the total divergence providing relative estimates of genetic divergence.

This technique can evaluate diversity among large number of germplasm lines providing relative estimates of genetic divergence at both inter and intra cluster level.

The statistical distance (D) serves as index of genetic diversity for the selection of parent with diverse origin, as effective breeding for desired traits requires careful selection of parents with a wide genetic base to enhance genetic gain (Lapitan et al., 2007). In the present investigation, genetic diversity among the 33 genotypes of finger millet was estimated following the Mahalanobis's $D^{2}$ statistics (1936).

\section{Materials and Methods}

The experimental material consisted of 33 diverse finger millet genotypes grown in randomized block design with two replications at Department of Plant Biotechnology, University of Agricultural Sciences, GKVK, Bengaluru during Kharif, 2018. Each entry was grown in a single row of 2 meters length and the spacing maintained was $22.5 \mathrm{~cm}$ between rows and $10 \mathrm{~cm}$ between plants within a row. All the recommended crop production and protection practices were followed during the crop growth period to raise a healthy crop. Fifteen yield and yield related traits were evaluated to assess the magnitude of genetic divergence among the 33 cultivated teraploid genotypes of finger millet.

Five competitive plants from each genotype in each row were randomly selected and observations were recorded on days to $50 \mathrm{per}$ cent flowering, plant height $(\mathrm{cm})$, number of tillers plant ${ }^{-1}$, number of productive tillers plant $^{-1}$, number of ear heads plant ${ }^{-1}$, main ear head length $(\mathrm{cm})$, number of fingers per main ear, finger length $(\mathrm{cm})$, finger width $(\mathrm{cm})$, peduncle length $(\mathrm{cm})$, main ear head weight (g), total ear head weight plant ${ }^{-1}(\mathrm{~g})$, shoot dry weight $(\mathrm{g})$, test weight $(\mathrm{g})$ and grain yield per plant (g). Days to 50 per cent flowering was noted on single row basis, where 50 per cent of the plants in each row started flowering. The mean of five plants was subjected to multivariate analysis, to estimate genetic divergence by using Mahalannobis (1936) $\mathrm{D}^{2}$ statistic as described by Rao (1952). On the basis of $\mathrm{D}^{2}$ values genotypes were grouped into different clusters according to Tocher's method given by Rao (1952). 


\section{Results and Discussion}

Based on the estimates of $\mathrm{D}^{2}$, the 33 genotypes were grouped into 10 clusters following the Tocher's method as described by Rao (1952). The composition of ten different clusters is represented in the table 1 and figure 1. The cluster II and cluster IV were composed of 9 genotypes each and cluster I had 8 genotypes and all other remaining 8 were solitary clusters. The intra and inter-cluster $\mathrm{D}$ values were obtained from $\mathrm{D}^{2}$ value of all the 10 clusters are summarized in table 2 . The present study revealed the inter cluster distance (D) was ranged from 11.47 to 46.61. The maximum inter cluster distance was observed between cluster VII and cluster VIII ( $D=46.61)$ followed by $\mathrm{D}$ value of 42.22 observed between cluster VII and cluster II. The minimum inter cluster distance was observed between cluster VII and cluster III $(\mathrm{D}=11.47)$.

Cluster I showed maximum inter-cluster distance with cluster VIII $(\mathrm{D}=31.97)$ followed by cluster II $(\mathrm{D}=28.04)$, whereas, it recorded minimum inter-cluster distance with cluster III $(\mathrm{D}=13.90)$ (Table 2). Cluster II recorded maximum inter-cluster distance with cluster VII ( $\mathrm{D}=42.22)$ followed by cluster III (D =36.90), whereas minimum inter-cluster distance was reported with cluster IX (D $=16.21$ ). Similarly, the maximum inter-cluster D values for cluster III was observed with cluster VIII (38.64), cluster IV with cluster VII $(D=35.54)$, cluster V with cluster VII $(\mathrm{D}=30.92)$, cluster VI with cluster VIII $(D=30.16)$, cluster VII with cluster VIII $(\mathrm{D}=46.61)$, cluster VIII with cluster $\mathrm{X}$ $(D=38.89)$ and cluster IX with cluster $X$ $(\mathrm{D}=21.36)$.

Similarly intra cluster distance was ranged from 0.00- 14.10 and maximum intra cluster distance $(D=14.10)$ was observed in cluster IV, which is comprised of 9 genotypes. The intra cluster distance of 11.26 and 10.79 was observed in cluster I and cluster II, which are comprised of 8 and 9 genotypes respectively. The zero intra-cluster distance was observed in cluster III, V, VI, VII, VIII, XI and X, as these clusters were composed of single genotypes.

The extent of genetic diversity in finger millet using $\mathrm{D}^{2}$ statistics has been also reported earlier by Jain et al., (1981), Jaylal and Haider (1994), Vadivooet al., (1998), Kadam (2007), Anantharaju and Meenakshiganesan (2008), Krishnappa et al., (2009), Kumar et al., (2010), Desai (2012), Das et al., (2013), Karad and Patil (2013), Suryanarayan et al., (2014) and Devaliya et al., (2017). Kumar et al., (2010) also grouped the 140 genotypes of finger millet into 10 non-overlapping clusters. All these studies have suggested the geographical diversity within a plant population cannot be equated with the genetic diversity. The inter and intra cluster distance (D) obtained in this study were very high.

The extent of diversity observed among the clusters is concurrent with the variability of these genotypes for different traits. The genotype GE4568 (cluster VII) has the highest mean value for grain yield, GE1200 (cluster VIII) was the early flowering type.

Whereas, the GE492 (cluster X) was late flowering type. Genetically diverse germplasm lines are often produce high heterotic effects and wide spectrum of variability can be generated by using distantly related genotypes in a breeding programme (Griffing and Lindson, 1954).

The magnitude of variability generated largely depends on the degree of divergence in the germplasm, the observed pattern of clustering in the present study suggest that, these diverge genotypes can be effectively utilized in hybridization programme to generate highly variable segregating population for crop improvement. 
Table.1 The distribution of 33 genotypes of finger millet into 10 different clusters on the basis of Mahalanobis $\mathrm{D}^{2}$ statistics

\begin{tabular}{|c|c|c|}
\hline Cluster & No. of genotypes & \begin{tabular}{c} 
Name of genotypes \\
\hline I
\end{tabular} \\
\hline II & 8 & $\begin{array}{r}\text { GE4596, PR202, GE156, L5, GE3510, } \\
\text { GE2358, GE199, GE4983 }\end{array}$ \\
\hline III & 1 & $\begin{array}{r}\text { GE1264, GE4738, GE113, GE1377, GE1050, } \\
\text { GPU28, GE2866, GE4201, GE4731 }\end{array}$ \\
\hline IV & 9 & GE5118 \\
\hline V & 1 & GE2963, GE4832, GE3461, GE2735, GE12, \\
\hline VI & 1 & GE4963, GE4995, GE292, GE4547 \\
\hline VII & 1 & PS1681 \\
\hline VIII & 1 & GE4568 \\
\hline IX & 1 & GE1200 \\
\hline $\mathbf{X}$ & 1 & GPU67 \\
\hline & & \\
\hline
\end{tabular}

Fig.1 Clustering of 33 finger millet genotypes based on Tocher's method using 15 morphological traits

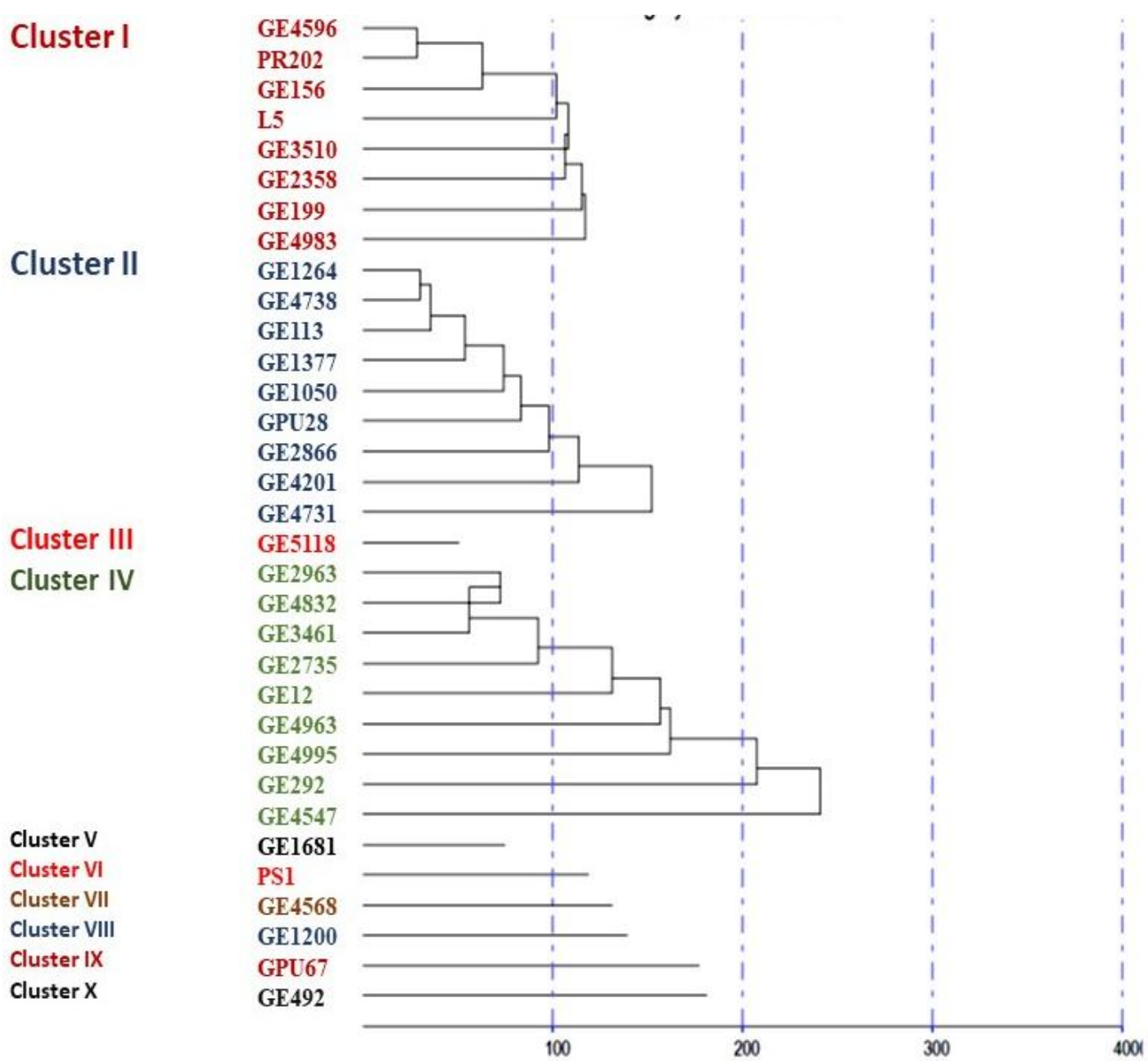


Table.2 Average inter and intra-cluster distance (D) values of 10 clusters of 33 genotypes of finger millet

\begin{tabular}{|c|c|c|c|c|c|c|c|c|c|c|}
\hline & Cluster I & Cluster II & Cluster III & Cluster IV & Cluster V & Cluster VI & Cluster VII & Cluster VIII & Cluster IX & Cluster X \\
\hline Cluster I & 11.26 & 28.04 & 13.90 & 22.88 & 17.27 & 17.88 & 17.87 & 31.97 & 26.13 & 24.04 \\
\hline Cluster II & & 10.79 & 36.90 & 20.36 & 16.76 & 20.38 & 42.22 & 18.80 & 16.21 & 25.38 \\
\hline Cluster III & & & 0.00 & 28.79 & 24.59 & 25.94 & 11.47 & 38.64 & 34.15 & 31.27 \\
\hline Cluster IV & & & & 14.10 & 19.31 & 21.15 & 35.54 & 26.61 & 20.41 & 22.50 \\
\hline Cluster V & & & & & 0.00 & 18.25 & 30.92 & 18.20 & 19.89 & 26.79 \\
\hline Cluster VI & & & & & & 0.00 & 27.70 & 30.16 & 17.57 & 13.71 \\
\hline Cluster VII & & & & & & & 0.00 & 46.61 & 38.77 & 31.34 \\
\hline Cluster VIII & & & & & & & & 0.00 & 23.48 & 38.89 \\
\hline Cluster IX & & & & & & & & & 0.00 & 21.36 \\
\hline Cluster X & & & & & & & & & & 0.00 \\
\hline
\end{tabular}

* Values in bold represent intra-cluster $\mathrm{D}$ values 
Table.3 The cluster mean values of 15 characters in 33 genotypes of finger millet

\begin{tabular}{|c|c|c|c|c|c|c|c|c|c|c|}
\hline & Cluster I & Cluster II & Cluster III & Cluster IV & Cluster V & Cluster VI & Cluster VII & Cluster VIII & Cluster IX & Cluster X \\
\hline Days to $50 \%$ flowering & 79 & 75.44 & 78 & 82.33 & 71 & 85 & 84 & 61 & 82 & 96 \\
\hline Plant height $(\mathrm{cm})$ & 82.86 & 57.29 & 92.4 & 78.02 & 74.3 & 36.6 & 88.3 & 55.7 & 61.45 & 64.3 \\
\hline No. of tillers & 4.2 & 5.03 & 3.1 & 5.06 & 5.5 & 10 & 4.5 & 6.59 & 3.8 & 4.8 \\
\hline Productive tillers & 3.91 & 4.72 & 3.1 & 4.31 & 5.2 & 9 & 4.5 & 5.7 & 3.8 & 4.4 \\
\hline No. of earheads plant ${ }^{-1}$ & 4.99 & 5.8 & 3.2 & 5.61 & 6.2 & 9.6 & 5.2 & 8.22 & 3.75 & 4.7 \\
\hline Main earhead length $(\mathrm{cm})$ & 7.06 & 4.82 & 9.4 & 8.12 & 5.09 & 3.8 & 6.94 & 6.33 & 5.8 & 4.74 \\
\hline No. of fingers per main ear & 6.73 & 6.31 & 7.1 & 6.34 & 4.6 & 5.6 & 7.3 & 7.1 & 4.6 & 7.85 \\
\hline Finger length (cm) & 6.4 & 3.67 & 8.74 & 7.38 & 4.39 & 3.6 & 5.95 & 6.56 & 5.41 & 3.77 \\
\hline Finger width (cm) & 0.93 & 0.84 & 1.2 & 0.77 & 1.07 & 0.7 & 0.95 & 0.6 & 0.85 & 1.04 \\
\hline Peduncle length (cm) & 23.94 & 19.11 & 22.3 & 21.2 & 28 & 14.2 & 21.8 & 21.75 & 17.3 & 16.8 \\
\hline Main earhead weight (g) & 6.27 & 2.5 & 6.68 & 2.38 & 3.98 & 2.5 & 6.94 & 2.75 & 2.63 & 3.58 \\
\hline Total earhead weight/plant & 29.54 & 15.8 & 34.99 & 20.66 & 21.25 & 25.2 & 40.31 & 12.94 & 14.3 & 23.45 \\
\hline Shoot dry weight (g) & 24.12 & 12.74 & 23.16 & 24.2 & 12.13 & 14.21 & 26.9 & 15.45 & 13.84 & 25.99 \\
\hline Test weight (g) & 3.96 & 3.52 & 3.9 & 3.79 & 3.9 & 3.4 & 3.8 & 4.33 & 4.45 & 3 \\
\hline Grain yield per plant (g) & 24.26 & 12.22 & 27.58 & 14.82 & 17.94 & 20.82 & 31.89 & 15.91 & 21.3 & 17.69 \\
\hline
\end{tabular}

Values indicated in bold are the maximum mean value of each character among the cluster 
Table.4 The per cent contribution of fifteen characters toward total divergence

\begin{tabular}{|c|c|c|c|}
\hline SL. No & Character & $\begin{array}{c}\% \text { contribution } \\
\text { towards divergence }\end{array}$ & $\begin{array}{l}\text { No. of times } \\
\text { ranked first }\end{array}$ \\
\hline 1 & Days to $50 \%$ flowering & 33.14 & 175 \\
\hline 2 & Plant height (cm) & 1.14 & 6 \\
\hline 3 & Number of tillers/plant & 11.74 & 62 \\
\hline 4 & $\begin{array}{c}\text { Number of productive } \\
\text { tillers/plant }\end{array}$ & 2.08 & 11 \\
\hline 5 & Number of earheads plant ${ }^{-1}$ & 0.00 & 0 \\
\hline 6 & Main earhead length $(\mathrm{cm})$ & 0.19 & 1 \\
\hline 7 & Number of fingers/ main ear & 0.00 & 0 \\
\hline 8 & Finger length $(\mathrm{cm})$ & 14.77 & 78 \\
\hline 9 & Finger width $(\mathrm{cm})$ & 0.38 & 2 \\
\hline 10 & Peduncle length (cm) & 1.89 & 10 \\
\hline 11 & Main earhead weight (g) & 5.87 & 31 \\
\hline 12 & Total earhead weight/plant (g) & 15.15 & 80 \\
\hline 13 & Shoot dry weight (g) & 0.00 & 0 \\
\hline 14 & Test weight (g) & 0.00 & 0 \\
\hline 15 & Grain yield per plant (g) & 13.45 & 71 \\
\hline & Total & $100 \%$ & \\
\hline
\end{tabular}


The analysis of cluster mean performance within the cluster provides an opportunity to identify desirable genotypes within the divergent cluster. The cluster mean for all the 15 characters revealed wide range of variability among the cluster for different traits (Table 3). The results clearly depicted the appreciable amount of difference among cluster means for most of the characters. For example, the total ear head weight per plant has cluster mean value ranging between 12.94 gram (cluster VIII) and 40.31 gram (cluster VII). Similarly for the days to 50 per cent flowering, cluster mean values ranged between 61 days (cluster VIII) to 96 days (cluster X) (Table 3). The cluster VII possessing the solitary genotype (GE4568) emerged as the most divergent genotypes with a highest mean value for grain yield per plant, total ear head weight per plant, shoot dry weight and main ear head weight. The cluster VII also maintained higher cluster distance with the cluster VIII (GE1200), which is earliest to flower. The cluster III also possess only one genotype (GE5118), which had highest cluster mean value for main ear head length, finger length, finger width and plant height.

The results revealed wide range of variability among the cluster for days to 50 per cent flowering, total ear head weight per plant, shoot dry weight, grain yield per plant, plant height, main ear head weight and productive tiller. Similar wide range of variability among germplasm for yield and yield related traits in finger millet has been reported by Reddy et al., (1993), Jayal and Haider (1994), Anantharaju and Meenakshiganesan(2008), Karad and Patil (2013), Devaliyaet al., (2017) and Sapkalet al., (2019).

The per cent contribution of various characters towards genetic divergence among 33 genotypes were evaluated using Wilk's criterion (Table 4). The highest contribution towards genetic divergence was contributed by days to 50 per cent flowering with a share of 33.14 per cent followed by total ear head weight per plant (15.15\%), finger length $(14.77 \%)$, grain yield per plant $(13.45 \%)$ and number of tillers $(11.74 \%)$. The observed results in the present study, indicate the scope for utilization of genotypes from divergent clusters for judiciously combining the yield and yield contributing traits for developing superior cultivar. For example, the solitary cluster VII (GE4568) recorded highest mean value for grain yield per plant, total ear head weight per plant, main ear head weight and shoot dry weight, while the cluster III (GE5118) recorded highest mean value for 
length, finger length, finger width and plant height. Therefore, the genotypes in these solitary cluster can be used as parental lines for hybridization to complement all the seed yield and yield related traits and to produce superior cultivar.

\section{Acknowledgement}

The authors express their gratitude to All India Coordinated Research Project on Small Millets (AICRPSM), GKVK, Bengaluru for providing seed material. Authors are also thankful to ISCB-Ragi network and Department of Science Technology (DST) Fund for Improvement of S\&T infrastructure in universities \& higher educational institutions (FIST) for providing research facilities.

\section{References}

Anantharaju, P. and Meenakshiganessan. N., 2008. Genetic divergence studies in finger millet (Eleusine coracana L. Gaertn). Indian J. Agric. Res.,42(2): 120-123.

Chethan, S. and Malleshi, N. G., 2007. Finger millet polyphenols: Optimization of extraction and the effect of $\mathrm{pH}$ on their stability. Food Chem., 105(2): 862870.

Das, R., Sujatha, M., Pandravada, S. R., and Sivasankar, A., 2013. Genetic divergence studies in finger millet (Eleusine coracana (L.) Gaertn.) germplasm. Trends in Biosci.,6(4): 373-376.

Desai, S. V., 2012. Genetic diversity studies in finger millet (Eleusine Coracona). M.Sc.(Agri) thesis, MPKV, Rahuri.

Devaliya, S. D., Singh, M. and Intawala, C. G., 2017. Genetic Divergence Studies in Finger Millet [Eleusine coracana (L.) Gaertn.]. Int. J. Curr. Microbiol. Appl. Sci., 6(11): 2017-2022
Goron, T. L. and Raizada, M. N., 2015. Genetic diversity and genomic resources available for the small millet crops to accelerate a New Green Revolution. Front. plant science, 6 (157): 1-18.

Griffing, B. And Lindston, E. W., 1954. A study of combining abilities of corn inbreds having varying proportions of cornbelt and non- corn belt germplasm. Agronomy J., 46: 545-552.

Jain, A. K., Dhagat, N. K. and Tiwari, A. S., 1981. Genetic divergence in finger millet. Indian J Agric. Sci.,64(10): 715-716.

Jaylal, S. N. and Haider, Z. A. 1994. Genetic divergence in finger millet (Eleusine coracana Gaertn L.). Indian J. of Agric. Sci., 64(10): 715-716.

Kadam, D. D., 2007. Genetic architecture on finger millet (Eluesine coracana). Int. J. of Agric. Sci., 3(2): 104-107.

Karad, S. R. and Patil, J. V., 2013, Assessment of genetic diversity among finger millet (Eleusine coracana L.) genotypes. Int. J of Integr. Sci. Innov. Tech., 2(4):37-43.

Krishnappa, M., Ramesh, S., Chandraprakash, J., Jayarame, G. and Doss, D. D., 2009. Breeding potential of selected crosses for genetic improvement of finger millet. J. of SAT Agri. Res., 7: 1-6.

Kumar, D., Tyagi, V., Ramesh, B. and Pal, S., 2010. Genetic diversity in finger millet (Eleusine coracana L.). Crop Imp., 37(1): 25-28.

Lapitan, V. C., Brar, D. S., Abe, T. and Redona, E. D., 2007. Assessment of genetic diversity of Philippine rice cultivars carrying good quality traits using SSR markers. Breed. Sci.,57(4): 263-270.

Mahalanobis, P. C., 1936. On the generalized distance in statistics. National Institute of Science of India.

Rao, C. R., 1952. Advanced statistical 
methods in biometric research, John Wiley and Sons Inc., New York.

Reddy, K. R., Sameer, C. V., Kumar, C., Reddy and Reddy, K. H. P., 1993. Genetic divergence in ragi (Eleusine coracana Gaertn L.) Annals. of agric.Res., 14 (4): 411-415.

Sapkal, S. R., Bhavsar, V. V., Barhate, K. K. and Sarika, N. K., 2019. Correlation and Path Analysis for Different Characteristics in Germplasm of Finger Millet (Eleusine coracana (L.) Gaertn.). Int. J. Curr. Microbiol. Appl. Sci., 8(1): 2319-7706.

Sood, S., Joshi, D.C., Chandra, A. K. and Kumar, A., 2019. Phenomics and genomics of finger millet: current status and future prospects. Planta, 9:1-21.

Suryanarayana, L., Sekhar, D. and Rao, V. D.,
2014, Genetic variability and divergence studies in finger millet (Eleusinecoracana (L.) Gaertn.). Int. J. Curr. Microbiol. Appl. Sci., 3 (4):931936.

Upadhyaya, H. D., Gowda, C. L. L., Pundir, R. P. S., Reddy, V. G. and Singh, S., 2006. Development of core subset of finger millet germplasm using geographical origin and data on 14 quantitative traits. Genet. Resour. Crop. Ev, 53(4): 679-685.

Vadivoo, A. S., Joseph, R. and Ganesan, N. M., 1998. Genetic variability and diversity for protein and calcium contents in finger millet (Eleusine coracana (L.) Gaertn) in relation to grain color. Plant Foods Hum. Nutri., 52(4): 353-364.

\section{How to cite this article:}

Sunil Subramanya, A. E. and Ravikumar, R. L. 2020. Genetic Divergence Studies in Cultivated Tetraploid Finger Millet [Eleusine coracana (L.) Gaertn] genotypes using $\mathrm{D}^{2}$ analysis. Int.J.Curr.Microbiol.App.Sci. 9(01): 109-118. doi: https://doi.org/10.20546/ijcmas.2020.901.012 